\title{
Robotic Glove Menggunakan Hybrid Functional Electrical Stimulation (Fes) dan Exoskeleton untuk Rehabilitasi Tangan Manusia
}

\author{
Achmad Ilham Fanany Al Isyrofie, Achmad Arifin, dan Fauzan Arrofiqi \\ Departemen Teknik Biomedik, Institut Teknologi Sepuluh Nopember (ITS) \\ e-mail: arifin@bme.its.ac.id
}

\begin{abstract}
Abstrak-Disabilitas yang terjadi pada tangan manusia menunjukkan masalah yang serius bagi beberapa orang. Salah satu penyebab terjadinya disabilitas pada fungsi sistem gerak manusia ialah terjadinya kerusakan pada sistem saraf pusat, atau Spinal Cord Injury (SCI). Penyakit stroke termasuk salah satu jenis SCI yang menyebabkan penderitanya mengalami penurunan pada sistem sensori dan motorik pada tubuh. Pada penelitian ini, akan dikembangkan suatu alat yang merupakan gabungan dari exoskeleton dan Functional Electrical Stimulation(FES). Exoskeleton adalah kerangka alat untuk dapat melatih gerakan menggenggam dan memperkuat daya genggam dengan bantuan external power. FES merupakan sebuah teknik yang memanfaatkan arus elektrik untuk mengaktifkan bagian saraf yang mengalami gangguan atau disfungsi karena berbagai gangguan neurologis. Sisi kebaruan dari metode rehabilitasi ini terletak pada optimasi penggunaan exoskeleton untuk mengurangi kelelahan otot akibat stimulasi yang berlebihan dari FES. Exoskeleton dengan panjang $\mathbf{7 7 . 2}$ mm dapat menghasilkan gerakan mekanik yang mendorong terjadinya gerakan fleksi dan ekstensi. Electrical stimulator menghasilkan output berupa gelombang kotak dengan karakteristik lebar pulsa $200 \mu \mathrm{S}$, frekuensi $20 \mathrm{~Hz}$, dan range amplitudo sebesar $0.2 \mathrm{~V}$ hingga $130 \mathrm{~V}$. Output hasil stimulus tersebut disalurkan menuju otot Flexor Digitorum, sehingga dapat menghasilkan gerakan fleksi dan ekstensi pada jari-jari tangan. Metode hybrid FES dan exoskeleton dengan amplitudo stimulasi yang berubah-ubah dan kecepatan motor sebesar 1.36 rpm dapat mencapai gerakan fleksi dalam rentang waktu 23.95 detik, sedangkan gerakan ekstensi dapat dicapai dalam rentang waktu 20.16 detik. Penelitian selanjutnya disarankan mengembangkan metode kontrol yang digunakan agar dapat menghasilkan gerakan yang lebih smooth dan selaras, memilih sensor yang lebih akurat, dan memilih motor yang berukuran lebih kecil dengan torsi lebih tinggi.
\end{abstract}

Kata Kunci-Exoskeleton, Functional Electrical Stimulation, Spinal Cord Injury, Stroke.

\section{PENDAHULUAN}

$\mathrm{D}$ ISABILITAS yang terjadi pada tangan manusia menunjukkan masalah yang serius bagi beberapa orang karena melemahnya fungsi sistem gerak pada manusia. Salah satu penyebab terjadinya disabilitas pada fungsi sistem gerak manusia ialah terjadinya kerusakan pada sistem saraf pusat, atau Spinal Cord Injury (SCI).Penyakit stroke termasuk salah satu jenis SCI yang menyebabkan penderitanya mengalami penurunan pada sistem sensori dan motorik pada tubuh. Stroke merupakan hilangnya fungsi otak dikarenakan adanya gangguan suplai darah ke otak [1]. Sebagai akibatnya, area yang terdampak pada otak tidak dapat bekerja secara normal, yang menyebabkan ketidakmampuan menggerakkan satu atau lebih anggota badan pada salah satu sisi tubuh. Ciri-ciri

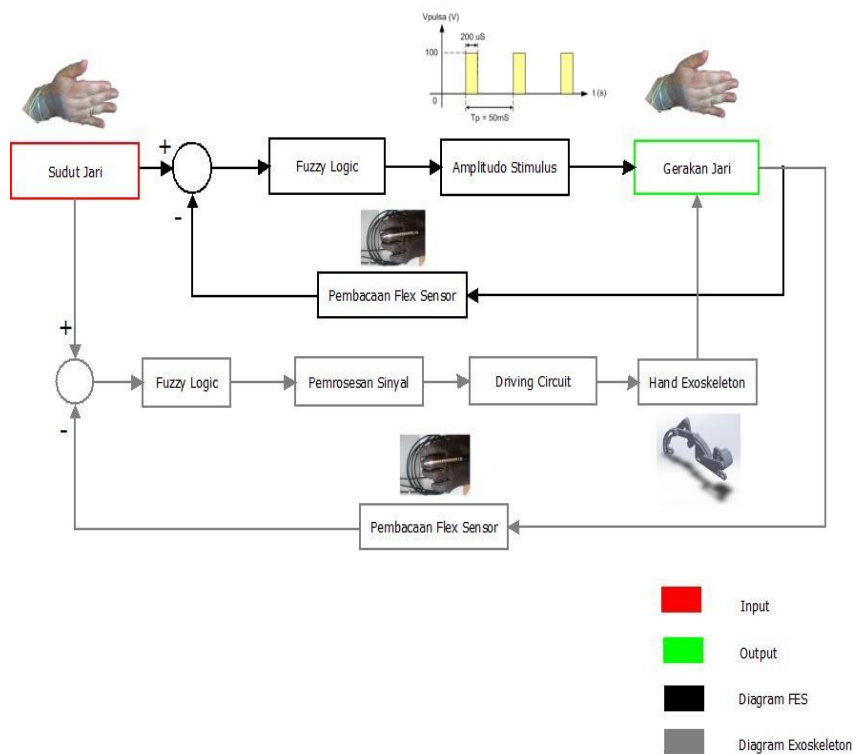

Gambar 1. Diagram Blok Sistem

penderita penyakit stroke diantaranya adalah kelumpuhan pada wajah serta beberapa anggota badan, berbicara tidak lancar, dan terjadinya gangguan penglihatan. Penyakit stroke ini juga memiliki kemungkinan untuk melumpuhkan seluruh bagian tubuh. Setelah pasien sembuh dari penyakit stroke, maka persendian pada anggota tubuh yang lumpuh akan menjadi lebih kaku. Jumlah penderita penyakit stroke di Indonesia tahun 2013 berdasarkan diagnosis Tenaga Kesehatan (Nakes) diperkirakan sebanyak 1.236.825 orang $(7,0 \%)$, sedangkan berdasarkan diagnosis Nakes, gejala diperkirakan sebanyak 2.137 .941 orang $(12,1 \%)$ [2].

Beberapa akibat dari penyakit stroke yang melanda bagian upper limb dari tubuh manusia menyebabkan melemahnya gerakan jari tangan, dimana jari tangan lebih kaku dalam melakukan gerakan menggenggam. Oleh karena itu, beberapa metode untuk merehabilitasi pasien pasca stroke dikembangkan. Beberapa metode rehabilitasi untuk pasien pasca stroke yang dikembangkan yaitu exoskeleton yang dapat melatih fungsi gerak tangan dengan memanfaatkan external power dan FES yang menggunakan arus elektrik untuk mengaktivasi sel saraf yang menstimulasi bagian tangan yang mengalami disabilitas. Kedua metode ini dimanfaatkan untuk dapat mengembalikan fungsi tangan ke kondisi normal seperti mekanisme menggenggam dan membuka tangan sehingga dapat meningkatkan kualitas hidup dari orang dengan disabilitas pada upper limb.

FES adalah sebuah teknik yang menggunakan aliran elektrik untuk mengaktivasi sel saraf yang mengalami kelumpuhan sebagai hasil dari Spinal Cord Injury (SCI), head 
injury, stroke dan gangguan neurologis lainnya [3]. FES utamanya digunakan untuk mengembalikan fungsi pada orang dengan disabilitas. Namun, bila FES digunakan secara terus-menerus, otot objek yang distimulasi dapat mengalami kelelahan. Selain itu, penggunaan FES juga harus memperhatikan penempatan elektroda agar mendapatkan hasil yang diinginkan. Apabila penempatan elektroda tidak tepat, ketika proses stimulasi dilakukan, gerakan yang terjadi bisa saja tidak seperti yang diinginkan atau tidak terjadi gerakan dan menyebabkan kulit mengalami luka seperti luka bakar. Exoskeleton adalah kerangka alat yang dipasangkan pada sarung tangan untuk dapat melatih gerakan menggenggam dan memperkuat daya genggam dengan bantuan external power.

Pada penelitian ini, dilakukan penggabungan antara metode FES dan Exoskeleton dengan mengoptimalkan penggunaan exoskeleton untuk mengurangi kelelahan otot akibat stimulasi yang berlebihan dari FES. Hasil pengembangan ini diharapkan dapat membantu aktifitas dari orang-orang yang mengalami disabilitas, khususnya disabilitas pada bagian tubuh upper limb(tangan).

\section{METODE}

Sistem gabungan antara FES dan exoskeleton mengombinasikan antara metode external power yang memanfaatkan Exoskeleton dan metode stimulasi elektrik yang memanfaatkan FES. Exoskeleton diaktuasi menggunakan motor servo, dalam mengatur gerakan fleksi dan ekstensi. Sinyal input untuk exoskeleton berasal dari switch yang kemudian dilakukan pengolahan sinyal yang meliputi akuisisi sinyal, pengondisian sinyal, dan pemrosesan sinyal menggunakan STM32F103C8. Kemudian dilakukan sistem aktuasi dan kontrol menggunakan servo motor dan Flex sensor yang dihubungkan dengan mikrokontroler. Sinyal dari sensor dikonversi ke satuan tegangan melalui Analog to Digital Converter (ADC) dan mikrokontroler. Kontroler menentukan perbedaan antara genggaman pada benda dengan diameter besar (Large Diameter), genggaman pada benda dengan diameter kecil (Small Diameter),genggaman pada benda dengan diameter sedang (Medium Warp), dan mekanisme release. Hal ini dapat dilakukan dengan mengatur nilai threshold pada algoritma kontrol. Apabila nilai threshold memenuhi nilai yang diinginkan, sinyal keluaran akan dikirim dari mikrokontroler menuju ke aktuator.

Pada sistem FES, kontraksi otot akan mengakibatkan pergerakan tubuh sehingga terjadi perubahan nilai pada sensor. Perubahan nilai ini kemudian diolah oleh mikrokontroller, yang meliputi pengolahan sinyal dan kontroler fuzzy, selanjutnya Digital to Analog Converter (DAC) mengeluarkan tegangan yang mempengaruhi tegangan output stimulus. Diagram blok dari sistem gabungan FES dan exoskeleton ditunjukkan pada Gambar 1.

\section{A. Desain Exoskeleton}

Desain dari exoskeleton mempertimbangkan beberapa aspek, diantaranya adalah bentuk, ukuran, biaya, dan berat [4]. Berat dan biaya dari exoskeleton sangat penting untuk pengguna dalam desain yang diusulkan. Biaya yang terjangkau akan dapat bersaing dengan biaya terapi
Tabel 1.

Antropometri Jari Tangan Laki-Laki

\begin{tabular}{lllll}
\hline \multicolumn{4}{c}{ Antropometri Jari Tangan Laki-Laki } \\
\hline No & $\begin{array}{l}\text { Dimensi } \\
\text { Tubuh }\end{array}$ & Rerata(mm) & $\begin{array}{l}\text { Laki- Laki } \\
\text { Koefisien } \\
\text { Korelasi }\end{array}$ & Persamaan Prediksi \\
\hline 1 & TB & 1704 & - & - \\
2 & Pij & 61.4 & 0.645 & $-59.1+0.707 \mathrm{~TB}$ \\
3 & Pjt & 77.2 & 0.518 & $-16.1+0.548 \mathrm{~TB}$ \\
4 & Pjtg & 85.0 & 0.446 & $-9.4+0.554 \mathrm{~TB}$ \\
5 & Pjm & 80.7 & 0.408 & $3.4+0.453 \mathrm{~TB}$ \\
6 & Pjk & 63.6 & 0.280 & $13.8+0.292 \mathrm{~TB}$ \\
\hline \hline
\end{tabular}

Tabel 2.

Antropometri Jari Tangan Wanita

\begin{tabular}{|c|c|c|c|c|}
\hline \multirow[b]{2}{*}{ No } & \multirow[b]{2}{*}{$\begin{array}{l}\text { Dimensi } \\
\text { Tubuh }\end{array}$} & \multicolumn{3}{|c|}{ Laki- Laki } \\
\hline & & $\operatorname{Rerata}(\mathrm{mm})$ & $\begin{array}{l}\text { Koefisien } \\
\text { Korelasi }\end{array}$ & Persamaan Prediksi \\
\hline 1 & TB & 1573 & - & - \\
\hline 2 & Pij & 57.0 & 0.442 & $-39.3+0.061$ TВ \\
\hline 3 & Pjt & 69.7 & 0.465 & $-19.6+0.057 \mathrm{~TB}$ \\
\hline 4 & Pjtg & 79.0 & 0.286 & $19.8+0.038 \mathrm{~TB}$ \\
\hline 5 & Pjm & 72.4 & 0.252 & $22.2+0.032 \mathrm{~TB}$ \\
\hline 6 & Pjk & 56.3 & 0.291 & $5.9+0.032 \mathrm{~TB}$ \\
\hline
\end{tabular}

konvensional. Berat dari exoskeleton kurang dari 45 gram. Desain dari exoskeleton harus pas di jari dan gerakannya harus dapat mengikuti jari orang yang mengalami disabilitas. Input torsi diatur sebesar $30 \mathrm{~N}$-mm sesuai dengan motor yang dipilih. Pada penelitian ini, torsi dapat menggerakkan jari secara perlahan, sehingga cocok untuk penderita stroke ringan. Pada pasien dengan stroke sedang, torsi dari motor dapat ditingkatkan dengan ukuran yang sama namun sedikit menambah berat dari alat. Proses perancangan dan analisa sistem menggunakan Solidworks TM dan Autodesk Inventor TM

Prototype dari robotic finger sendiri memiliki 2 slider, 5 links, 10 bolt, dan 1 motor. Motor yang digunakan ialah stepper motor untuk mengaktuasi exoskeleton dan mengunci posisi sendi pada tempatnya. Stepper motor digunakan karena dapat melakukan pergerakan rotasi dan pergerakan linear bidireksional.

Ukuran dari desain exoskeleton menyesuaikan dengan ukuran jari tangan manusia. Ukuran jari tangan manusia berbeda-beda sehingga diperlukan pengukuran antropometri tangan . Pengukuran antropometri tangan yang dibutuhkan meliputi ukuran panjang ibu jari (Pij), panjang jari telunjuk (Pjt), panjang jari tengah (Pjtg), panjang jari manis (Pjm), dan panjang jari kelingking (Pjk). Ukuran dari desain exoskeleton yang direalisasikan merujuk pada Tabel 1 dan Tabel 2 .

\section{B. Desain FES}

Perancangan hardware FES dapat dibagi menjadi 4 bagian. Hardware FES meliputi rangkaian boost converter, rangkaian amplitude regulator, rangkaian pembangkit pulsa, serta rangkaian driver channel. Hardware FES juga membutuhkan sinyal Pulse Wave Modulator (PWM) dan sinyal Digital to Analog Converter (DAC) yang diperoleh dari mikrokontroller STM32F103C8. Diagram blok FES dapat dilihat pada Gambar 2.

Rangkaian boost converter merupakan rangkaian converter yang menghasilkan tegangan keluaran yang lebih besar dari tegangan sumber atau masukannya. Rangkaian boost converter direalisasikan menggunakan non-isolated boost converter karena kemudahan dalam desain dan penggunaan komponen yang sedikit sehingga perangkat yang dihasilkan bisa berukuran kecil dan ringan. Pada penelitian 


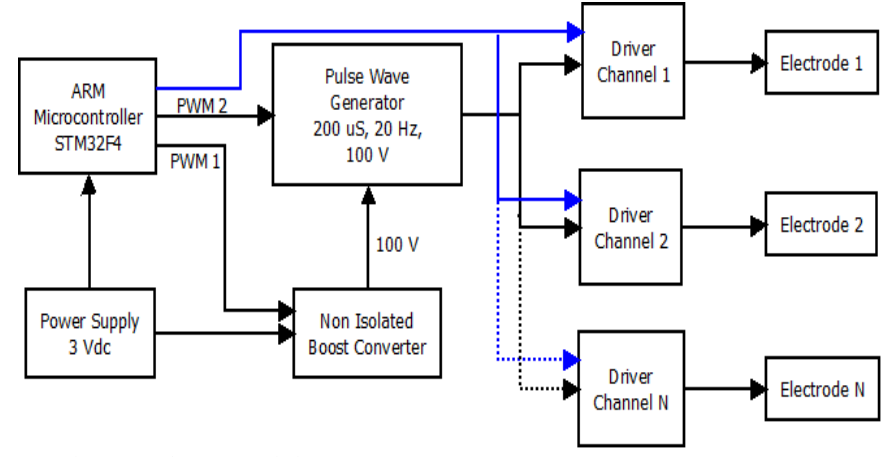

Gambar 2. Diagram Blok FES

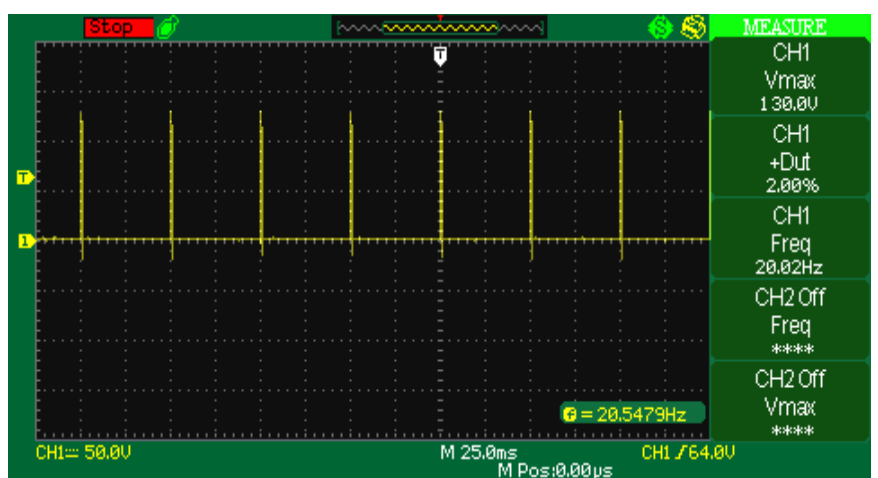

Gambar 3. Keluaran pulsa $200 \mu \mathrm{S}, 20 \mathrm{~Hz}$ pada rangkaian pembangkit pulsa

ini, rangkaian boost converter mendapatkan input frekuensi sebesar $20 \mathrm{KHz}$. Sementara itu, tegangan input yang diberikan sebesar $5 \mathrm{~V}$. Pada rangkaian boost converter, transistor yang digunakan untuk pengaturan Pulse Wave Modulator (PWM) perlu memenuhi beberapa kriteria yaitu :

1. Tegangan $\mathrm{V}_{\mathrm{CE}}$ lebih besar dari tegangan output maksimal boost converter

2. Arus yang dapat dilewatkan oleh transistor harus lebih besar dari arus output boost converter

Berdasarkan kedua kriteria tersebut, digunakan transistor tipe MPSA42 (NPN). Selain itu, perlu ditentukan jenis dioda yang akan digunakan dalam rangkaian boost converter ini. Pada rangkaian ini digunakan dioda tipe 1N4148 karena dioda ini memiliki kecepatan switching yang tinggi, sehingga dapat membantu menaikkan tegangan output boost converter menjadi lebih tinggi.

Rangkaian amplitude regulator merupakan rangkaian yang berfungsi untuk mengubah nilai amplitudo input pembangkit pulsa berdasarkan nilai input rangkaian amplitude regulator. Pada rangkaian ini digunakan IC LM358 sebagai amplifier amplitudo. Output dari IC LM358 digunakan sebagai input basis transistor, dan dilakukan penguatan nilai boost oleh transistor. Selanjutnya dilakukan pengaturan tegangan dengan menggunakan metode pembagian tegangan antara output dari boost converter dengan input dari DAC sehingga didapatkan tegangan stimulator yang diinginkan

Rangkaian pembangkit pulsa merupakan rangkaian half $\mathrm{H}$ bridge yang berfungsi untuk menghasilkan pulsa dengan lebar pulsa $200 \mu \mathrm{S}$ serta frekuensi $20 \mathrm{~Hz}$. Proses menghasilkan pulsa menggunakan transistor PNP pada T7 serta transistor NPN pada T6. Kedua kaki kolektor transistor terhubung, sehingga nilai dari kedua transistor ini selalu berkebalikan. Pada bagian belakang kedua transistor ini diberikan IC inverter serta transistor T5.
Tegangan Keluaran Amplitude Regulator

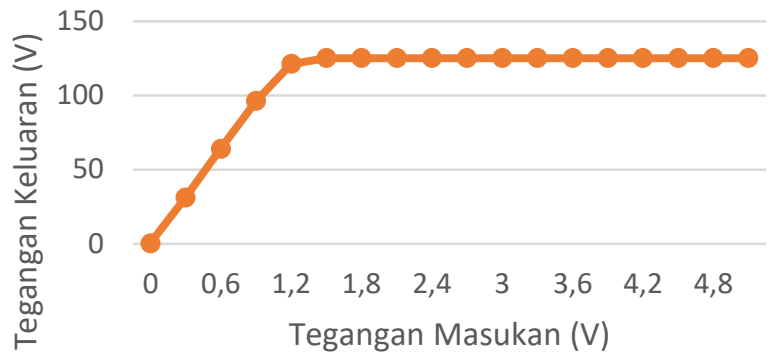

- Tegangan Keluaran Amplitude Regulator (V)

Gambar 4. Grafik keluaran rangkaian amplitude regulator

\section{HASIL DAN DISKUSI}

\section{A. Pengujian Rangkaian Boost Converter}

Pengujian terhadap rangkaian boost converter dilakukan dengan mengubah nilai frekuensi dan duty cycle sinyal PWM 1 untuk memperoleh tegangan keluaran boost converter yang sesuai. Berdasarkan data percobaan yang diperoleh, ketika frekuensi masukan pada sinyal PWM1 diubah-ubah terjadi perubahan tegangan keluaran boost converter. Tegangan keluaran yang dihasilkan pada saat duty cycle diatas $60 \%$ menunjukkan perubahan yang linier, dimana semakin tinggi frekuensi masukan maka semakin tinggi pula tegangan keluaran dari rangkaian boost converter yang dihasilkan. Kemudian, ketika duty cycle dibawah 60\%, tegangan keluaran boost converter akan semakin menurun ketika nilai frekuensi masukan dinaikkan. Ketika duty cycle dari frekuensi masukan sinyal PWM1 diubah, tegangan keluaran boost converter juga mengalami perubahan, dimana semakin tinggi duty cycle yang diterapkan maka nilai tegangan keluaran boost converter juga mengalami kenaikan. Berdasarkan pengujian ini, rangkaian boost converter menghasilkan tegangan keluaran yang memuaskan pada frekuensi $20 \mathrm{KHz}$ dan duty cycle $90 \%$.

\section{B. Pengujian Rangkaian Pembangkit Pulsa}

Hasil pengujian rangkaian pembangkit pulsa dapat dilihat pada Gambar 3. Berdasarkan Gambar 3, dapat diketahui bahwa keluaran dari rangkaian pembangkit pulsa yang dirancang sudah memenuhi ekspektasi, dimana rangkaian pembangkit pulsa ini dapat menghasilkan sinyal pulsa sebesar $130 \mathrm{~V}, 20 \mathrm{~Hz}$. Keluaran dari rangkaian ini dapat dikatakan sudah memenuhi ekspektasi, sehingga dapat disalurkan menuju otot lengan manusia. Ketika nilai DAC yang digunakan sebagai masukan untuk rangkaian amplitude regulator diubah-ubah, maka nilai tegangan yang dihasilkan oleh pembangkit pulsa juga mengalami perubahan.

\section{Pengujian Rangkaian Amplitude Regulator}

Hasil pengujian dari rangkaian amplitude regulator dapat dilihat pada Gambar 4. Berdasarkan gambar grafik tersebut dapat disimpulkan bahwa penggunaan rangkaian amplitude regulator sudah dapat membuat tegangan keluaran yang akan masuk ke rangkaian pembangkit pulsa menjadi linier, dan lebih mudah untuk mengatur tegangan keluarannya. 


\section{Grafik Perubahan Resistansi Flex Sensor}

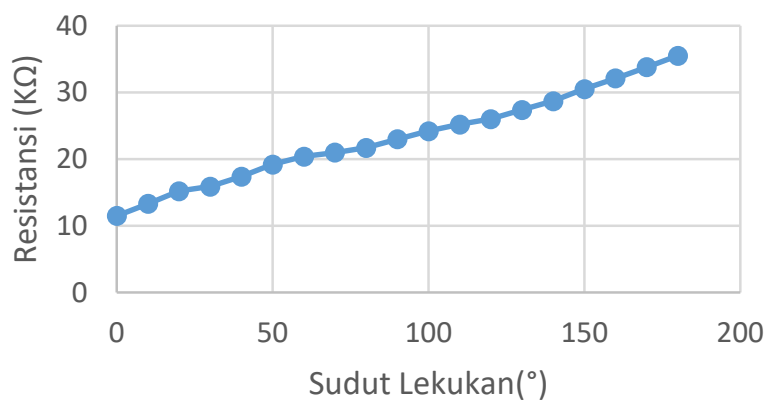

Gambar 5. Grafik perubahan resistansi flex sensor

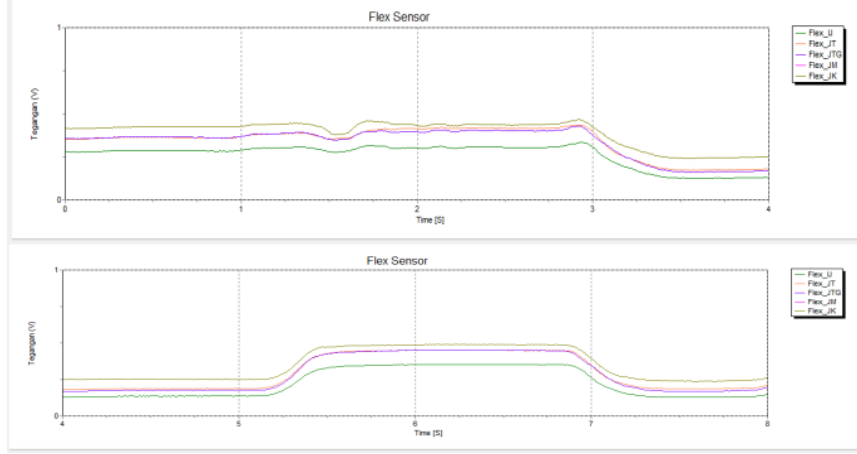

Gambar 6. Hasil pembacaan data flex sensor

\section{Pengujian Flex Sensor}

Pengujian flex sensor dilakukan dengan melakukan pengukuran nilai resistansi flex sensor terhadap perubahan sudut lekukan yang dapat dilihat pada Gambar 5. Berdasarkan Gambar 5, dapat diketahui bahwa semakin tinggi besar sudut lekukan, maka resistansi flex sensor yang dihasilkan semakin besar. Pengujian selanjutnya dilakukan dengan melakukan proses ADC Hasil pembacaan dari flex sensor dapat dilihat pada Gambar 6. Pada detik ke 0 hingga detik ke 3, kelima flex sensor berada dalam keadaan melengkung. Pada detik ke 3 hingga detik ke 5, kelima flex sensor berada dalam keadaan datar. Pada detik ke 5 hingga detik ke 7, kelima flex sensor berada dalam keadaan melengkung, sedangkan detik ke 7 hingga detik ke 8 kondisi flex sensor berada dalam keadaan datar.

\section{E. Pengujian Exoskeleton}

Prosedur pengujian dilakukan untuk menguji hasil dari gerakan mekanik exoskeleton. Hasil dari gerakan yang dihasilkan exoskeleton dapat dilihat pada Gambar 7. Prototype exoskeleton terhubung dengan stepper motor yang akan mengakomodasi gerakan exoskeleton. Perubahan kecepatan motor akan dipengaruhi driving circuit yang mendapatkan input dari pengolahan data oleh mikrokontroler. Desain exoskeleton yang direalisasikan memiliki panjang $77.2 \mathrm{~mm}$. Berdasarkan pengujian yang telah dilakukan, exoskeleton yang dipasang pada jari telunjuk dan jari manis telah mampu menghasilkan gerakan melengkung untuk gerak fleksi dan ekstensi jari tangan.

\section{F. Pengujian Hybrid FES dan Exoskeleton}

Pengujian hybrid FES dan exoskeleton diterapkan pada subjek dengan memakai sarung tangan yang telah dilengkapi

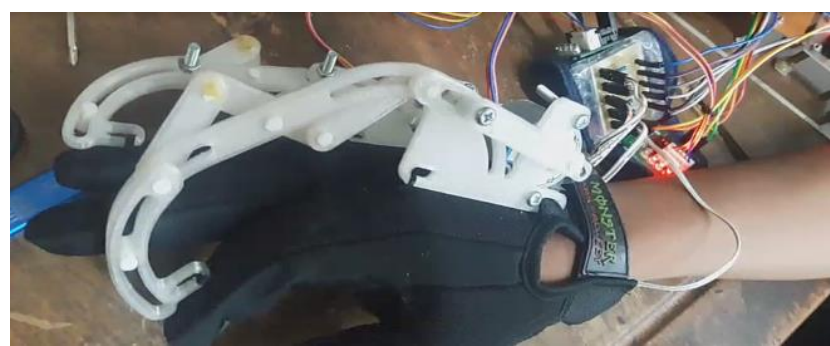

Gambar 7. Hasil gerakan mekanik exoskeleton

flex sensor dan exoskeleton, serta dipasang elektroda pada bagian otot flexor digiorum. Pengujian dilakukan dengan dua kali gerakan fleksi dan ekstensi. Pengujian diterapkan pada tiga subjek yang berbeda dan menghasilkan gerakan fleksi dan ekstensi dengan durasi yang bervariasi.

Hasil pengujian sistem pada subjek 1 dapat dilihat pada Gambar 8. Pengujian dilakukan dengan dua kali gerakan fleksi dan ekstensi. Gerakan fleksi dan ekstensi pertama membutuhkan waktu 40.24 detik. Gerakan fleksi pertama dapat dicapai setelah 22.54 detik, sedangkan gerakan ekstensi pertama dapat dicapai setelah 17.7 detik. Gerakan fleksi dan ekstensi kedua membutuhkan waktu 40.24 detik. Gerakan fleksi kedua membutuhkan waktu 19.84 detik, sedangkan gerakan ekstensi kedua membutuhkan waktu 20.04 detik. Kecepatan rotasi motor yang dihasilkan oleh stepper motor 28BYJ-48 yang terpasang pada exoskeleton sebesar $1.49 \mathrm{rpm}$.

Hasil pengujian sistem pada subjek 2 dapat dilihat pada Gambar 9. Gerakan fleksi dan ekstensi pertama membutuhkan waktu 47.3 detik. Gerakan fleksi pertama dapat dicapai setelah 22.55 detik, sedangkan gerakan ekstensi pertama dapat dicapai setelah 24.75 detik. Gerakan fleksi dan ekstensi kedua membutuhkan waktu 44.95 detik. Gerakan fleksi kedua membutuhkan waktu 21.85 detik, sedangkan gerakan ekstensi kedua membutuhkan waktu 23.1 detik. Kecepatan rotasi motor yang dihasilkan oleh stepper motor 28BYJ-48 yang terpasang pada exoskeleton sebesar $1.3 \mathrm{rpm}$.

Hasil pengujian sistem pada subjek 3 dapat dilihat pada Gambar 10. Gerakan fleksi dan ekstensi pertama membutuhkan waktu 47.85 detik. Gerakan fleksi pertama dapat dicapai setelah 34.08 detik, sedangkan gerakan ekstensi pertama dapat dicapai setelah 13.77 detik. Gerakan fleksi dan ekstensi kedua membutuhkan waktu 44.44 detik. Gerakan fleksi kedua membutuhkan waktu 22.85 detik, sedangkan gerakan ekstensi kedua membutuhkan waktu 21.59 detik. Kecepatan rotasi motor yang dihasilkan oleh stepper motor 28BYJ-48 yang terpasang pada exoskeleton sebesar $1.3 \mathrm{rpm}$.

Gerakan yang dihasilkan stimulasi FES dan rotasi motor pada exoskeleton dapat berjalan dengan aman. Gerakan fleksi yang telah diujikan pada subjek rata-rata membutuhkan waktu 23.95 detik, sedangkan gerakan ekstensi membutuhkan waktu 20.16 detik. Kecepatan stepper motor yang dihasilkan rata-rata sebesar $1.36 \mathrm{rpm}$. Perbedaan waktu yang dibutuhkan setiap subjek untuk menghasilkan gerakan fleksi dan ekstensi dipengaruhi oleh beberapa faktor diantaranya adalah, perbedaan ukuran otot subjek, penempatan elektroda, dan adanya friksi antar part pada exoskeleton yang menghalangi gerakan motor.

Perubahan tegangan keluaran electrical stimulator belum bisa menghasilkan perubahan nilai tegangan yang smooth karena kontrol yang digunakan masih memiliki rule yang terbatas. Penelitian selanjutnya dapat menerapkan metode kontrol dengan lebih baik sehingga dapat memperoleh hasil 


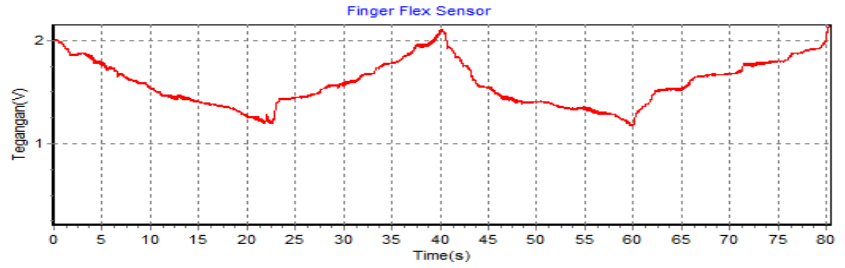

Gambar 8. Hasil gerakan jari pada subjek 1

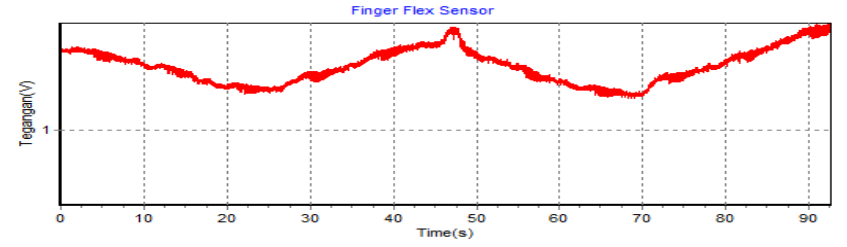

Gambar 9. Hasil gerakan jari pada subjek 2

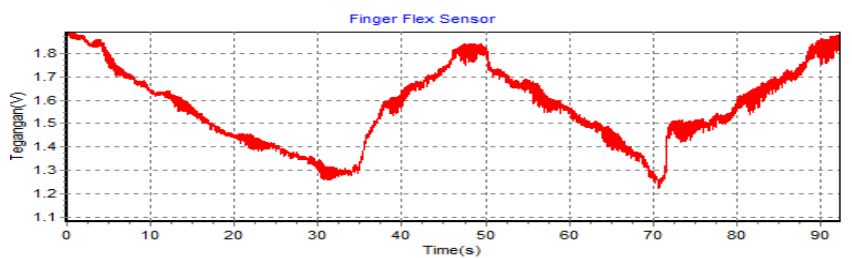

Gambar 10. Hasil gerakan jari pada subjek 3

gerakan yang lebih smooth dan selaras antara stimulasi dari electrical stimulator dan external power dari exoskeleton yang menghasilkan gerakan fleksi dan ekstensi yang lebih optimal.

\section{KESIMPULAN}

Peletakan posisi elektroda pada permukaan kulit otot tangan sangat berpengaruh terhadap kontraksi otot yang dihasilkan oleh pulsa listrik dari stimulator. Penempatan elektroda yang tepat untuk menghasilkan gerakan fleksi dan ekstensi jari adalah otot flexor digitorum profundus dan extensor digitorum. Electrical stimulator direalisasikan menggunakan rangkaian boost converter, rangkaian amplitude regulator, rangkaian pembangkit pulsa dan mikrokontroller STM32F103C8. Berdasarkan hasil pengujian, electrical stimulator dapat menghasilkan keluaran dengan range antara $0.2 \mathrm{~V}$ hingga $130 \mathrm{~V}$. Sedangkan untuk exoskeleton, desain yang telah direalisasikan dengan panjang $77.2 \mathrm{~mm}$ sudah dapat menghasilkan gerakan yang dapat mendorong jari untuk melakukan gerakan fleksi dan ekstensi dengan memanfaatkan gerakan dari stepper motor 28BYJ-48. Desain exoskeleton yang direalisasikan ditempatkan pada jari telunjuk dan jari manis untuk mengompensasi gerakan fleksi dan ekstensi.

Gerakan yang dihasilkan oleh stimulasi dari electrical stimulator dan exoskeleton dapat diamati perubahannya dengan melihat grafik perubahan sudut flex sensor yang terdapat pada user interface. Grafik yang terdapat pada user interface telah dapat menghasilkan nilai perubahan yang linear dengan perubahan sudut jari yang dibaca oleh flex sensor, sehingga dapat dilakukan analisa berdasarkan grafik yang ditampilkan.

Metode hybrid FES dan exoskeleton dengan amplitudo stimulasi yang berubah-ubah dan kecepatan motor sebesar $1.36 \mathrm{rpm}$ dapat mencapai gerakan fleksi dalam rentang waktu 23.95 detik, sedangkan gerakan ekstensi dapat dicapai dalam rentang waktu 20.16 detik. Metode ini telah dapat menghasilkan gerakan fleksi dan ekstensi, namun tingkat keselarasan antara stimulasi dari electrical stimulator dengan external power dari exoskeleton masih rendah dikarenakan penerapan logic control dengan rule yang masih terbatas.

Penelitian selanjutnya disarankan menggunakan elektroda yang lebih kecil sehingga dapat diperoleh keakurasian penempatan elektroda. Selain itu, flex sensor yang digunakan memiliki tingkat keakurasian yang kurang optimal, sehingga penelitian ke depan disarankan untuk meningkatkan keakurasian sensor atau menambahkan sensor lain untuk mendapatkan hasil yang optimal. Desain exoskeleton yang diterapkan bisa dirancang lebih minimalis dan menggunakan motor dengan ukuran lebih kecil dan torsi yang lebih besar sehingga dapat menghasilkan gerakan yang lebih optimal dan menjadikan alat lebih ringan serta nyaman bagi pengguna. Penelitian selanjutnya juga disarankan mengembangkan metode kontrol yang digunakan agar dapat menghasilkan gerakan yang lebih smooth dan selaras.

\section{DAFTAR PUSTAKA}

[1] R. Nithya, S. D. Bharathi, and P. Poongavanam, "Design of orthotic assistive exoskeleton for human hand," in 2015 IEEE International Conference on Engineering and Technology (ICETECH), 2015, pp. 16.

[2] "Kementerian Kesehatan Republik Indonesia." [Online]. Available: https://www.kemkes.go.id/article/view/17051800002/sebagian-besarpenderita-hipertensi-tidak-menyadarinya.html. [Accessed: 09-May2020].

[3] D. K. Vilaili, "Sistem Closed Loop Functional Electrical Stimulus (FES) pada Aktivitas Menggenggam Menggunakan Informasi Sensori Posisi Jarak dan Gaya Haptic,' Institut Teknologi Sepuluh Nopember, 2017.

[4] T.-H. Hsu, Y.-C. Chiang, W.-T. Chan, and S.-J. Chen, "A finger exoskeleton robot for finger movement rehabilitation," Inventions, vol. 2, no. 3, p. 12, 2017. 